\title{
Human Resources Managers as Custodians of The KING III CODE
}

\author{
Frank de Beer and Daniel Hercules du Toit \\ Optentia Research Focus Area, North-West University, Vanderbijlpark \\ Accepted: November 2014
}

\begin{abstract}
The objective of this research was to perform an exploratory study on the knowledge and understanding of the King III code among Human Resources (HR) managers in South African companies. The King III code is a comprehensive international corporate governance regime which addresses the financial, social, ethical and environmental practices of organisations. HR management plays a role in managing corporate governance by using the King III code as a guideline. The main research questions were: Does HR management know, understand, apply, and have the ability to use the King III code in terms of ethical decision-making? What role does HR management play in corporate governance? A random sample of available HR managers, senior HR consultants and HR directors was taken and semi-structured interviews were conducted. The results indicated that the respondents had no in-depth knowledge of the King III code. They did not fully understand the King III code and its implications nor did they use it to ensure ethical management. The themes most emphasised by the participants were: culture, reward and remuneration, policies and procedures and performance management. The participants emphasised the importance of these items and HR's role in managing them.
\end{abstract}

Key words: ethical behaviour, ethics, King III code, corporate governance, HR management

JEL: L530

\section{$1 \quad$ Introduction}

The King III code became necessary because of the anticipated new Companies Act and the changing trends in international governance (Meyer, 2009). As for the King I and the King II codes, the King III committee endeavoured to be at the forefront of international corporate governance. Meyer (2009), the Institute of Directors (2009) and Price Waterhouse Coopers (2009) emphasised that the King III code was neither a legal document nor a mere best practice guideline, but was a comprehensive international corporate governance regime. Companies are expected to comply, since compliance is considered to be essential to best practice. If a company did not comply and an incident occurred, it could be required to explain why it had not complied. The consequences for non-compliance could be severe, as an incident could tarnish the company's reputation (Institute of Directors, 2009; Meyer, 2009; Price Waterhouse Coopers, 2009). The King III code advocates an integrated approach to good governance, in the interest of a wide range of stakeholders. The code also highlights the importance of ethics at the board, management and staff levels, and, in particular, the importance of an ethical culture. The King III code embraces the fundamental principles of responsible financial, social, ethical and environmental practice (Institute of Directors, 2009).

The first chapter of the King III code deals with ethical leadership and corporate citizenship. Price Waterhouse Coopers (2009) indicated that the King III code states that companies must be responsible corporate citizens. That implies an ethical relationship of responsibility between a company and the society in which it operates. Price Waterhouse Coopers (2009) further indicates that companies, apart from rights, also have legal and moral obligations. The company should protect, enhance and invest in the well-being of the economy, society and the natural environment (Institute of Directors, 2009). The objective of this research is to perform an exploratory study to identify the position of HR management as a custodian of the King III code, determine HR management's knowledge and understanding of the King III code and identify the role of HR management in corporate governance. 


\section{Literature review}

The HR profession in general is currently moving towards a role in which it is seen as more than just a strategic business partner. HR managements are regarded as the drivers of business success by becoming HR governors in organisations (Roodt \& Meyer, 2010). This means that HR managements are expected to govern compliance in their organisations. Some of the ethical challenges organisations and their HR management have to face include those of fraud, corruption, theft, espionage, sabotage, money laundering, lies, crime, cybercrime, nepotism, favouritism, price fixing, poor governance and unethical behaviour. These economic realities indicate the need for HR management to become ethical leaders or role models. According to Ciulla (2004), employees generally perceive HR managers to be ethical and effective leaders. This being the case, HR managers have to manage and implement ethical cultures in their organisations by establishing clear ethical values (Meyer, 2009). In managing and implementing the ethical values of the organisation, HR managers can make use of several tools, such as an ethical code of conduct and no tolerance policies.

This study will focus on the King III code as a guideline for managing the ethical behaviour of all the employee levels in an organisation, including the directors. The majority of the King III code principles relate to corporate and human conduct, so they ultimately affect the management of an organisation's human resources (Kuper, 2006). The King III code can be a valuable tool for HR management (Meyer, 2009). It can guide the HR management as a strategic business partner, and assist with managing an ethical culture. Four moral duties are laid out in the King III code (Institute of Directors, 2009), to which directors should adhere: conscience inclusivity (with reference to stakeholders), competence, commitment and courage. These moral duties form the basis of any senior leadership role in an organisation and are part of any director's obligations and responsibilities. The concept of an organisation as a responsible corporate citizen is entrenched throughout the King III code. A corporate citizen has a social and moral standing in society, with all the related responsibilities. To be a responsible corporate citizen implies an ethical relationship of responsibility between the organisation and the society in which it operates; companies are held responsible for the triple bottom line, which consists of economic, social and environmental performance (Institute of Directors, 2009; Meyer, 2009).

The King III code also emphasises the other crucial HR matters, such as the need for a formal and transparent process of appointing new directors at the board level, performance assessment, formal orientation and mentoring of the directors, board remuneration and the continued professional training and development of new directors (Kuper, 2006). Roodt and Meyer (2010) maintain that HR management is specifically mentioned in the King III code as being important for the identification and mitigation of risks. Boards should annually report on risk and sustainability issues like social development, transformation, ethics, safety and AIDS (Institute of Directors, 2009). According to Meyer (2009), there is an implicit need for HR executives to interface at the board level to ensure full strategic-level compliance with governance requirements, and to champion adherence to ethical principles.

\section{Research method and sample}

The main research questions were:

- Does HR management know, understand, apply and have the ability to use the King III code in terms of ethical decision-making?

- What role does HR management play in corporate governance?

A qualitative study was conducted to investigate the research questions. This qualitative study can be defined as descriptive and exploratory. The field study was qualitative in nature, and a phenomenological research design was used. A phenomenological research design aims to describe the meaning of experiences of a phenomenon, topic or concept for various individuals (Creswell, 1998). A phenomenological design aims to obtain descriptions of experiences through 
first person accounts during interviews, for the purpose of understanding human behaviour (Creswell, 1998). As the aim of this research was to develop patterns and relationships of meaning, this design was found to be most applicable. The researcher conducted semi-structured interviews, the aim of which was not to get answers to particular questions nor to test hypotheses, but to gain an understanding of the participants' experience and the meaning they made of that experience regarding the King III report.

Purposive sampling was used to select HR managers, HR executives and HR directors (henceforth referred to as "senior HR managers" if they are individual or "HR management" if they are a group) from various South African industries. It was difficult to find candidates from the top levels of organisations who were willing to participate in the study, owing to the sensitive nature of the research topic. Five participants were selected, based on their roles, responsibilities and contributions to the field of HR and to their industries. The five respondents, who participated voluntarily, comprised one in the security industry, two in the services industry and two senior HR consultants who worked in different industries, including government. The participants' backgrounds were as follows:

Participant $A$ is an HR director at a company with approximately 700 employees throughout South Africa and Africa. The company is part of a group of companies and reports to a holding company. Participant A reports directly to the managing director and has been with the company for more than 10 years. Participant A holds a university degree.

Participant $B$ is an HR director at a security firm with approximately 4000 employees. Participant $\mathrm{B}$ reports directly to the managing director and has been with the company for three years. Participant B holds a Master's degree and is also a lecturer in the field of HR.

Participant $C$ is the chief executive officer for a board that regulates people practices and has been with the board for three years. The board has approximately $6000 \mathrm{HR}$ members in all the industries throughout South Africa. Participant $\mathrm{C}$ holds a $\mathrm{PhD}$ in the HR field and is also a professor in the HR department of a university.

Participant $D$ is the chief executive officer for his own consulting company, with approximately 20 employees. Participant D consults in South Africa and more widely in Africa in a wide variety of industries. Participant $\mathrm{D}$ holds a university degree.

Participant $E$ is an industrial psychologist at an HR consulting firm with approximately 50 employees and works in government and various industries. Participant E holds a Master's degree in Industrial Psychology.

Semi-structured interviews were conducted with the participants. The interviews were exploratory and the same open-ended questions were asked at all of them (Berg, 2007). The researcher emphasised the participants' perspective by acknowledging and treating them as the experts. The interviews were organised around the areas of particular interest, while also allowing flexibility in scope and depth. The researcher did not ask any leading questions, but posed openended questions, one at a time, clarifying unclear responses, and using probes.

The following questions were asked during the interviews:

- Have you ever heard about or used the King III code?

- In your opinion, how would/do you apply the King III code in your organisation?

- What part does HR management play in corporate governance?

- What guideline does HR management use to make ethical decisions?

After the five interviews had been completed, the questions were revised. No major revision was required. To clarify some of the data, the researcher interviewed the five candidates for a second time. All the interviews were recorded and the data was transcribed verbatim, corrected, edited and grouped into themes before being analysed and triangulated, as suggested by Berg (2007). The themes were coded, using the open coding method. The content of the interviews were then rated according to the identified themes.

The data was reviewed by an external party, who independently identified themes. This was done to reduce biasness. The external party was a registered chartered accountant at the South 
African Institute of Chartered Accountants (SAICA) and had in-depth knowledge of the King III code. The overlap indicated the credibility, dependability and conformability of the analysis.

The data integrity was ensured by applying Guba's strategies (Krefting, 1991) for qualitative research. These strategies ensured the trustworthiness of the findings. The following strategies were applied:

- Credibility: the credibility of the data reflects the accuracy and plausibility of the research study's findings. This includes checking the true value of the findings obtained by checking the field notes, the triangulation, peer examination and the independent coding.

- Transferability: ensures the applicability of the findings; this was obtained by comparing adequate descriptive data and dense description of the data.

- Dependability: consistency of the data which were acquired by means of keeping unprocessed material, giving a clear and full description of the research method, and using the same process during peer examination and the code-recode procedure.

- Conformability: the researcher applied the criterion of neutrality, or keeping a distance, so as not to influence the research; also using code-recode procedure.

The researcher made field notes during the interviews. According to De Vos, Strydom, Fouché and Delport (2011) and Berg (2007), field notes are a written account of what the researcher experienced during an interview. This includes factors like preconceptions, emotions, expectations and prejudices.

The study was approved by the North-West University's Vaal Triangle Campus ethics committee. A signed consent form was used to obtain permission from the participants; oral consent to record the interviews was sought. A password-protected computer hard drive was used for storing the recordings and transcriptions. The researcher made backups of the research data and stored these onto two different external hard drives. The researcher stored the hard drives securely in locations separate from those of the original hard drive.

The researcher protected the participants within all possible, reasonable limits from any physical discomfort that might emerge from the specific research. The researcher informed the respondents about the details of the interview, how long it would take and what would be done with the information gathered during the interview. The respondents could withdraw whenever they wished. The respondents selected for the interviews were candidates who voluntarily accepted to be part of the study. Owing to the sensitive nature of the subject, the candidates remained anonymous.

\section{$4 \quad$ Findings}

The research questions were aimed at determining whether HR managers were aware of how to ensure good corporate governance by using the King III code. After an analysis of the semistructured interviews, the frequency of recurring themes was established. These themes indicated the understanding and use of the King III code by the HR managers in the sample. The following recurring themes were identified:

\section{Culture recurred in five of the interviews.}

All the participants highlighted the importance of an ethical organisation culture. Two participants acknowledged the King III code and the guidelines it provides for governing the ethical culture of an organisation. All the candidates agreed that HR management has a role to play in creating an ethical culture by developing and implementing the organisation's code of ethics, policies and procedures and ensuring that the employees' values are aligned with those of the organisation. Quotations follow from some of the participants' interviews to illustrate their views on the role of HR management relating to an ethical organisational culture:

"The King code highlights the importance of ethics at board, management and staff levels, and in particular, the need for an ethical culture. However, to think that an ethical code in itself will instil a culture of ethics is short-sighted. HR must expand its role from 'steward' 
(which centres on workforce compliance and administration) to 'strategist' (which affects every governance, risk, and compliance issue with a human element."

"It is HR's role to provide information, develop ethical cultures and environments. HR as a profession needs to be professionalised in order to be taken seriously, because at this stage HR is only seen as an administrative function and not taken serious at board level or by management."

Reward and remuneration recurred in five of the interviews.

All the participants emphasised the importance of the governance of rewards and remuneration by the boards of organisations. They all agreed that the HR manager's role in reward and remuneration should be to develop, implement and monitor the remuneration policies and procedures, and to be part of the remuneration-related committees. Examples of participants' responses follow:

"The remuneration policy and procedure need to be clearly defined and adhered to. This will aid the organisation in paying out fair salaries and bonuses; what is important is that everything needs to be transparent and aligned with legislation."

"HR needs to ensure that salary benchmarking has been done on the job profiles as a clear guide of the job grade should be in place. Therefore, the offer made to an applicable candidate is fair and the organisation does not discriminate against any positions or people. The remuneration policy and procedures need to be clearly defined and adhered to."

Policies and procedures recurred in five of the interviews.

All the participants agreed that HR management should develop and implement policies and procedures for governing ethical behaviour. All the participants suggested and recommended that policies and procedures should comply with all the relevant legislation, and must be transparent and fair. They viewed this as the responsibility of the HR management. Examples of the participants' responses follow:

"They (HR management) should start by creating a framework where all the organisational policies and procedures are aligned to legislation and the King III code. Then the framework should be audited to ensure that the organisation and the framework adhere to the King III code."

"If a director is guilty of unethical behaviour, then HR needs to address the dilemma and follow the company's policy and procedures. HR needs to have the authority to do that, but this is an issue, as HR is not taken seriously by organisations and an action like this could cost the HR person his job."

Performance management recurred in five of the interviews

All five of the participants in this study believed that it was the HR management's responsibility to implement fair, transparent and ethical performance management in an organisation. The whole organisation should be subject to the performance management interventions by the HR management, including the board and the committees. These interventions include performance assessments, such as $360^{\circ}$ reviews. Establishing a sound performance management system in an organisation was seen as a crucial element in corporate governance. Examples of the participants' responses follow:

"The board of directors and chief executives are by definition also human resources which should be optimally utilised to ensure organisational profitability and productivity. Just like ordinary employees, individual directors, their board sub-committees and audit committes should also be subjected to the company's policies, procedures, regular 360-degree performance assessment and reviews that are governed by HR.",

"HR needs to implement fair and transparent performance management frameworks that are applicable to everyone in the organisation and interpreted the same." 
Risk and corporate governance recurred in three of the interviews

Three of the participants agreed that corporate governance was important and affected the organisation's risk profile. Two of the participants said that governance was the responsibility of either the finance or the risk department in their organisations. All three of the participants who cited risk or corporate governance believed that the HR management should create and implement an ethical code, policies and procedures that would address both legislation and the King III code requirements.

\section{Recruitment and selection recurred in three of the interviews.}

Three participants mentioned the HR management's role in recruitment and selection as good corporate governance, but they emphasised different aspects of this duty. Two pointed out the HR management's responsibility for recruiting the right people, who would be likely to be ethical; one participant emphasised that HR management should ensure that the recruitment and selection processes were fair and transparent and one said that HR management should use its competence to ensure that the board made ethical decisions.

Training, learning and development recurred in three of the interviews.

Two of the three candidates who cited training and development expressed their concern about the competence and skills level of the very HR managers who were responsible for skills development in organisations. The third candidate mentioned that some HR professionals responsible for skills development fabricated data for skills development submissions. All three candidates were referring to the HR managers who were responsible for skills development in general and not in their specific companies.

\section{Employment equity recurred in two of the interviews}

Both of the candidates who mentioned employment equity in the interviews felt that HR managers and HR professionals responsible for employment equity reporting did not understand the required equity information and consequently submitted incorrect figures or else unethically manipulated them. Both were referring to their perceptions of HR managers in general, and not specifically to their own companies.

Information technology (IT) recurred in two of the interviews.

Both of the interviewees who mentioned information technology felt that HR management should ensure that there were policies and procedures that would address the governance of information technology and employees' use of social networking. They saw social networks, such as Facebook and Twitter, as a potential threat to an organisation's ethical culture and brand.

Reporting and compliance recurred in two of the interviews.

Both of the participants who cited reporting and compliance in the interviews said that organisations should disclose and report on every practice, including HR matters. One of the participants recommended that the HR director should regularly present the board with a complete report on HR compliance, operational risks and recommendations on actions for mitigating risks.

From the interviews it was apparent that senior HR managers who took part in this study knew about the King III report, but were not familiar with its contents, or else did not completely understand the whole King III code and its implications for them as senior HR managers. They agreed in the interviews that HR management had a definite responsibility in corporate governance and should create an ethical relationship of responsibility between the company and the society in which it operated. The participants clearly indicated that they did not have models or decisionmaking frameworks to assist them in making ethically sound decisions.

\section{Discussion and conclusion}

From the findings it emerged that the participants believed that senior HR managers had the responsibility of managing good corporate governance from a people perspective by using the King III code as a guideline. HR managers should be established as the custodians of the King III 
code. This means HR managers must be competent in using and implementing the King III code, as well as in establishing an ethical culture to ensure that the organisation was a responsible corporate citizen. The HR managers who took part in the study did not know or understand the full King III code and its implications. There was agreement during the interviews that HR management has a definite responsibility in corporate governance to create an ethical relationship of responsibility between the company and the society in which it operates. The themes identified will be discussed next and the findings will be compared with the literature.

\section{Culture}

"Making ethical practices a priority is not about merely functioning with integrity or being seen to do so. Nor is it about being credible and competitive. It is about optimising the efficient functioning of the organisation. Organisations are, therefore, urged to make improving their ethical cultures a priority, because focusing on ethics is a fundamental aspect of good management practices" (ICAC, 1998:2). All the participants agreed in the interviews that an ethical culture in an organisation is very important. The Ethics Resource Centre (ERC, 2009:6) indicated that: "In a 'strong' ethical culture, ethical values matter and are apparent in the actions of employees (especially management), company policy and procedures, and decisions about who gets rewarded, who gets punished, and how to weather tough times." "In a 'weak' ethical culture, ethical values are not promoted and 'getting the job done' is far more important than getting the job done in the ethically right way" (ERC, 2009:16). The strength of an organisation's ethical culture is in the extent to which it prioritises doing the right things. All the participants in this study agreed that it was the HR management's responsibility to develop, implement and monitor the organisation's code of ethics, policies and procedures. One participant stated that HR managers should act ethically and become role models for the rest of the organisation. The South African Board for People Practice (SABPP, 2014b) is compiling professional practice standards for HR professionals in an attempt to elevate the profession to the level nnecessary for HR professionals to take on the new roles required.

\section{Reward and remuneration}

Du Plessis, Fouché and Van Wyk (2002) defined the employer's responsibility for remuneration as set out by the Basic Conditions of Employment Act. Remuneration is multi-faceted. It provides the means of satisfying the universal needs of all employees, namely safety, belonging, growth and self-esteem (Meyer, Abbott et al., 2011). Bussin, Nienaber and Blair (2012) are of the opinion that remuneration facilitates people's attraction, retention, engagement and motivation, especially those with key skills. Remuneration also fulfils a strategic role in helping the organisation meet its goals. According to Meyer, Abbott et al. (2011), variable or incentive pay in particular is used to communicate corporate strategy, focus people on outcomes they are able to influence, and reinforce key behaviours that reflect the values of the organisation. Nobody could possibly doubt that engaged, valued and achievement-focused employees boost organisational performance, both directly and through their ability to inspire and motivate others. Remuneration makes an important contribution to the achievement of the strategic goals of the organisation and it lies close to the heart of the employment relationship.

Remuneration can be a potentially contentious subject, as seen in the frequently conflicting viewpoints, beliefs and interests of different groups of stakeholders. Stakeholders have complex demands arising from, inter alia, increasingly sophisticated knowledge workers, globalisation and increased competition for talent (Meyer, Abbott et al., 2011). There is a strong move towards equal pay for work of equal value, which is now accepted practice in Europe. It is to be expected that South Africa will follow suit (Meyer, Abbott et al., 2011). In addition, the disparity in income nationally in South Africa is an important issue in a country with the greatest difference between the highest and lowest salaries. According to Bussin et al. (2012), this also necessitated ethical guidelines for remuneration and rewards. The participants in this study maintained that it was HR management's role to influence the inequality of the distribution of pay and benefits. All the participants in this study who mentioned reward and remuneration felt strongly about governance 
of the rewards and remuneration for organisational boards of directors. All the participants agreed that HR managers had a role to play in reward and remuneration by developing, implementing and monitoring the remuneration policies and procedures as well as being part of the remuneration committees.

Policies and procedures

Policies can be defined as the specific guidelines, methods, procedures, rules, forms and administrative practices that direct the thinking, decisions and actions of managers and employees (Ehlers \& Lazenby, 2010; Grobler, Wärnich, Carrell, Elbert \& Hatfield, 2006). Policies provide a basis for control, and promote coordination and consistency throughout organisations. An organisation's policies can play a significant role in the execution of its business strategy, and it is vital that the policies are formulated so as to support business strategies (Ehlers \& Lazenby, 2010). High-quality policies and procedures help managers to regulate events proactively and assist the organisation with the prevention of costly legal proceedings. Doing so also allows management to guide operations without constantly intervening, which contributes to the empowerment of the workforce (Ehlers \& Lazenby, 2010).

When considering the traditional managerial functions of planning, organising, leading and controlling, the use and development of policies can be viewed as a combination of the planning and controlling functions. In terms of combining the planning and controlling functions, the nature of policies and their close link to strategic management, as well as their intention of guiding decision-making and behaviour at the organisational level places the concept of policy firmly in the management field (Ehlers \& Lazenby, 2010). All the participants in the field study who cited policies and procedures agreed that HR managers should develop and implement policies and procedures in the organisation. All the participants suggested and recommended that all policies and procedures should comply with the relevant legislation, and must be transparent and fair.

\section{Performance management}

Meyer, Abbott et al. (2011) state that performance management is a systematic data-based approach to managing human behaviour in the workplace. Various tools are used to measure and manage performance, and the processes differ among organisations. However, the basic principles and process in most organisations result in targets being set and each individual's performance being measured against the achievement of these targets. All five of the participants believed that it was HR management's responsibility to implement fair, transparent and ethical performance management in an organisation. The whole organisation should be subject to the performance management interventions of HR management, including the board and the committees. Establishing an effective performance management system in an organisation is a crucial element of corporate governance. According to Meyer, Abbott et al. (2011), board directors and chief executive officers are, by definition, also human resources which should be optimally utilised to ensure organisational profitability and productivity. Like all other employees, individual directors, the board sub-committees and the audit committees should also be subject to $360^{\circ}$ performance assessment and review.

\section{Risk and corporate governance}

Meyer, Roodt and Robbins (2011) stated that HR management should gather information on people-related governance, risk and compliance issues. The HR director should present company directors with a complete report on the HR department's compliance and operational risks, recommend actions and accept responsibility for the application. Furthermore, HR management could assist the board in related areas, such as managing executive succession, providing board development and administrative services (Deloitte, 2008). Meyer, Roodt et al. (2011) state that, although human capital risks are mentioned in the King III code, this aspect deserves more prominence. As the Deloitte (2008:11) report asserted: "People and behaviour are often the biggest source of business risk". Hence, it is critical to ensure that people risks are included in a company's risk management plan. A comprehensive people risk analysis is needed, one that significantly transcends the current narrow focus on safety in high-risk environments such as 
factories and mines (Meyer, Roodt et al., 2011). The participants in this study also believed that corporate governance is very important and, when conducted correctly and by all the stakeholders, it can reduce the organisation's risk profile.

Meyer, Roodt et al. (2011) identified the following people risks: company culture, talent shortages and retention, incompetence, employee performance, unethical behaviour, low morale, grievances and disputes, excessive absenteeism, employee wellness, sabotage, workplace violence, and non-compliance with industry and other regulations and laws. In this study, most of these were pointed out by the participants. Deloitte (2008:11) states that "governance, risk and compliance challenges affect every part of the business - and every one of those challenges has a significant human component". The HR function should use its unique skills, knowledge and experience to help business leaders tackle governance, risk and compliance issues across the entire organisation. One of the participants in this study stated that the ethics of governance is addressed in the King III code, where the code states that the board should ensure that the company is seen to be a responsible corporate citizen.

\section{Recruitment and selection}

The participants in this study believed that HR management is responsible for recruiting ethical people. Meyer, Abbott et al. (2011) stated that identifying the recruitment potential of employees represents one of the most significant human resource activities any manager undertakes. To attract people who are deemed best-fit, both in terms of job requirements and organisational culture, the HR management should ensure that there is a sound recruitment policy in place which sets out the highest ethical and professional standards to be applied to this important function. Recruitment opens a window on the organisation, is an important branding opportunity, and gives rise to the legally recognised and enforceable contractual relationships necessary to safeguard the organisation against possible allegations of discrimination and/or unfair labour practice (Meyer, Abbott et al., 2011).

At the same time, it ensures that the terms and conditions of recruitment comply with an organisation's policy and the relevant employment legislation (Meyer, Abbott et al., 2011). The participants in this study supported this view and emphasised the role of HR departments in ensuring that recruitment processes are fair and transparent. The participants also believed that HR managers should use their skills and competencies to ensure that the board makes ethical decisions on recruitment and selection, and this includes succession planning as part of the staffing process. Succession planning features prominently in the King III code. HR management assists in finding the right people for important leadership positions, based on detailed criteria and specific competencies. The SABPP's national HR management standard (SABPP, 2014a) gives clear guidelines for HR management on ethical recruitment and selection.

\section{Training, learning and development}

Meyer, Abbott et al. (2011) stated that the term "learning" is often used to describe the development of the individual in an organisation. Training is often seen as something that an organisation imposes on its employees, who may view this as an irritation, perhaps even a burden. Learning, on the other hand, is often something that someone would do in their own time (Felstead, Fuller, Unwin, Ashton, Butler \& Lee, 2005). The participants in this study expressed their concern with the competence and skills levels of HR managers who are responsible for skills development in organisations. HR managers may overlook the development of board members' specific skills owing to their lack of understanding of which skills are needed. It is critical for the HR managers responsible for skills management to be knowledgeable and competent, and to ensure that competent board members are appointed. One candidate indicated that some HR professionals who are responsible for skills development fabricate data for skills audit submissions. The participants agreed that HR managers have a responsibility for the training and development of employees, and board members in particular, but felt that they currently lacked the skills to perform this function properly. 
Employment equity

Meyer, Abbott et al. (2011) explain that,

in terms of the Employment Equity Act No 55 of 1998, employment equity is concerned with two aspects of employment law, the prohibition of unfair discrimination in the workplace and the duty of designated employers to implement affirmative action programmes. The Act also requires all employers to take steps to promote equal opportunity in the workplace and to prohibit unfair discrimination in all employment policies and practices. In addition, employers are obliged to adopt and implement affirmative action measures for people from designated groups.

Meyer, Abbott et al. (2011) found that some organisations use skills development to manipulate and inflate their Broad Based Black Economic Empowerment (BBBEE) scorecard; adjusting the number of black employees who have undergone irrelevant and non-value adding training only for the sake of showing that they have trained a certain percentage of black people and can claim points on the BBBEE scorecard. The participants in this study also believed that HR managers and HR members who work with employment equity do not understand it and consequently submit wrong figures that are not based on the correct criteria, or else they unethically manipulate the figures. The fact that none of the participants mentioned the other critical aspects of ethical Employment Equity could indicate that they do not see themselves playing a role in ensuring them.

Information technology

Meyer, Abbott et al. (2011) indicate that most organisations today store the majority of their information by using computer technology. Depending on size and sophistication, this can range from e-mail on a single computer in a small organisation to large-scale technology systems covering all the aspects of the business. In many organisations, the use of information technology (IT) is governed by an Acceptable Usage Policy, which guides employees in what is acceptable or unacceptable. Aspects usually covered by such policies are the use of e-mail, the internet, storing information and notification of the levels of monitoring. In South Africa, there is legislation that assists in determining whether the organisation is behaving ethically in terms of IT. Moreover, the next decade is expected to be dominated by cybercrime, unlawful practices relating to internet fraud, and the abuse of social media and other forms of IT.

Meyer (2009) indicated that, in terms of the Electronic Communications and Transactions Act 25 of 2002, employees must be educated in the organisation's IT and systems policy and they must understand and adhere to it. Legislation governs how much privacy an employee has in the workplace. However, the organisation's policy can set levels of complete, partial or no privacy and, accordingly, the organisation monitors the employees' use of IT. Employees must have a clear understanding of the various legal issues involved when using an organisation's IT system (Meyer, Abbott et al., 2011). In this study it was found that HR management was not fully aware of its role in corporate governance regarding IT, although a whole chapter was dedicated to IT governance in the King III code. HR management is responsible for ensuring that all policies and procedures are applied to support the corporate governance of IT. Both of the participants in this study who cited IT felt that HR management should ensure that there were policies and procedures that would address the governance of IT. Organisations use information technology to communicate to and update customers and employees on products, services, news and events in the business. The pervasiveness of IT in business today mandates its governance as a corporate imperative.

Reporting and compliance

The King III code dedicated a complete chapter to integrated reporting and disclosures. One of the essential principles of the King III code is the view that governance, strategy and sustainability are inseparable (Price Waterhouse Coopers, 2009). Stakeholders also want to be assured of the quality of information. Integrated reporting ensures an increase in confidence and trust from all the stakeholders in the legitimacy of the organisation's actions. "By issuing an integrated report 
internally, a company evaluates its ethics, fundamental values and governance, and externally improves the trust and confidence which stakeholders have" (Institute of Directors, 2009:12). Price Waterhouse Coopers (2009:3) pointed to "the need for an annual integrated report that focuses on the impact of the organisation on the economic, environmental and social spheres". The Institute of Directors (2009:3) suggests that "organisations have therefore recommended integrated sustainability performance and integrated reporting to enable stakeholders to make a more informed assessment of the economic value of a company.

The integrated report should contain sufficient information to record how the company has both positively and negatively impacted on the economic life of the community in which it operated during the year under review, often categorised as environmental-, social- and governance issues (ESG)". Both of the participants who cited reporting and compliance in the interviews stated that organisations should disclose and report on all the practices relating to corporate governance, including HR matters. One of these participants recommended that the HR director should present the board with a complete report on HR compliance, operational risks and recommendations on actions to mitigate risks. By issuing integrated reports as prescribed, advised by the King III code, a company increases the trust and confidence of its stakeholders and the legitimacy of its operations.

The findings of this study indicated that senior HR managers do not have in-depth knowledge and understanding of the King III code, but they do know about it. They also take their roles in corporate governance seriously. HR management does not use the King III code, feeling that corporate governance is the responsibility of all the senior employees in the organisation and the relevant departments. They are unaware of the King III code as a useful tool in corporate governance. HR management feels that HR audits should be carried out both internally and externally to ensure ethical practices. The HR department plays a critical role in establishing ethical culture in organisations. HR management and the board of directors of the organisation should establish an ethical code of conduct, identifying and executing the organisation's ethical strategy. There is a need to professionalise HR, as HR departments are still seen largely as having an administrative function, without authority or credibility at the board level. HR professionals and management need a checklist to be followed in establishing an ethical culture based on the guidelines of the King III code. HR managers are seen as lacking the assertiveness to apply HR processes, such as performance management and $360^{\circ}$ feedback at the board level. They are thus assisting in creating the impression that boards of companies are "above policies and procedures". HR managers also seem to lack the skills and assertiveness to play a more decisive role in the selection and training of board members.

It is recommended that both the HR professionals and the HR management be trained more intensively on ethics, corporate governance and the HR function's role in corporate governance. Professional bodies should support HR managers in providing guidance and developmental interventions. The SABPP (2014a) is developing a Professional Practice Standards code. With the first and second King reports, HR management had a very limited role in terms of the codes. In the King III code the focus was more on effective leadership, sustainability and corporate citizenship, which all involve HR management. While HR management generally knew about the code, it was not sure how the code affected its HR functions. The researchers further recommend that HR professional bodies set HR standards in terms of ethics and corporate governance. The standards include an auditing process for HR practices. The HR professional bodies should ensure that the qualifications and training are more focused on developing and preparing HR management to become strategic business partners in organisations. With the development of the King IV code, the impact on the HR function is expected to be even greater, with more responsibility for the management of HR. HR managers will thus need a deeper understanding and should receive more extensive training in the application of the King IV code. 


\section{References}

BERG, B.L. 2007. Qualitative research methods for the social sciences $\left(6^{\text {th }}\right.$ ed.) Boston, United States of America: Pearson Education, Inc.

BUSSIN, M., NIENABER, R. \& BLAIR, C. 2012. Best practice paper - Remuneration. Johannesburg, South Africa: SABPP.

CIULLA, J.B. 2004. Ethics and leadership effectiveness. In J. Antonakis, A.T. Cianciolo \& R.J. Sternberg (eds.) The nature of leadership (pp. 302-327). Thousand Oaks: Sage Publications.

CRESWELL, J.W. 1998. Qualitative inquiry and research design: Choosing among five traditions. Thousand Oaks: Sage Publications.

DELOITTE. 2008. Taking the reins: HR's opportunity to play a leadership role in governance, risk management and compliance. Available at: http://www.deloitte.com/assets/Dcom-UnitedStates/Local\%20 Assets/Documents/us consulting TakingtheReins 091911.pdf [accessed 2012-11-10].

DE VOS, A.S., STRYDOM, H., FOUCHÉ, C.B. \& DELPORT, C.S.L. 2011. Research at grass roots: For the social sciences and human service professions ( $4^{\text {th }}$ ed.) Pretoria, South Africa: Van Schaik Publishers. DU PLESSIS, J.V., FOUCHÉ, M.A. \& VAN WYK, M.W. 2002. A practical guide to labour law $\left(5^{\text {th }}\right.$ ed.) Pretoria, South Africa: Lexis Nexis.

EHLERS, M.B. \& LAZENBY, J.A.A. (Eds.) 2010. Strategic management: South African concepts and cases ( $3^{\text {rd }}$ ed.) Pretoria, South Africa: Van Schaik Publishers.

ETHICS RESOURCE CENTRE. 2009. The importance of ethical culture: Increasing trust and driving down risk - 2009. Available at: http://www.ethics.org/files/u5/CultureSup4.pdf [accessed 2013-01-22].

FELSTEAD, A., FULLER, A., UNWIN, L., ASHTON, D., BUTLER, P. \& LEE, T. 2005. Surveying the scene: Learning metaphors, survey design and the workplace context. Journal of Education and Work, 18(4): 359-383.

GROBLER, P., WÄRNICH, S., CARREL, M., ELBERT, N. \& HATFIELD, R. 2006. Human resource management in South Africa ( $3^{\text {rd }}$ ed.) London: Thompson Learning.

INDEPENDENT COMMISSION AGAINST CORRUPTION (ICAC). 1998. Ethics - The key to good management. Available at: www.icac.nsw.gov.au [accessed 2011-11-08].

INSTITUTE OF DIRECTORS. 2009. King lll report and code of governance for South Africa - 2009. Available at: http://african.ipapercms.dk/IOD/KINGIII/kingiiireport/ [accessed 2012-10-16].

KREFTING, L. 1991. Rigor in qualitative research: The assessment of trustworthiness. The American Journal of Occupational Therapy, 45:214-222.

KUPER, L. 2006. Ethics - the leadership edge. Paarl: Zebra Press.

MEYER, M. 2009. HR: The way forward. SABPP opinion paper, 2009/10. Available at: http://www.sabpp. co.za/category/our-library-research-articles/hr-governance-and-ethics/ [accessed 2012-11-22].

MEYER, M., ABBOT, P., BAM, P., BECKER, I., BOTHA, C., BRAND, H. \& GIBBONS, P. 2011. Ethics in HR management: A guide for HR professionals and line managers. Johannesburg, South Africa: SABPP.

MEYER, M., ROODT, G. \& ROBBINS, M. 2011. Human resource risk management: Governing people risks for improved performance. South African Journal of Human Resource Management, 9(1), Art. \#366. Available at: http://dx.doi.org/10.4102/sajhrm.v9i1.366 [accessed 2012-11-22].

PRICE WATERHOUSE COOPERS. 2009. King's Council: Understanding and unlocking the benefits of sound corporate governance. Available at: http://www.pwc.co.za/en/king3/index.jhtml [accessed 2013-01-19].

ROODT, G. \& MEYER, M. 2010. HR's credibility crisis: Is it related to HR risk management? Johannesburg: SABPP.

SABPP. 2014a. National human resources management standard. Johannesburg, South Africa: SABPP. SABPP. 2014b. Draft HR professional practice standards. Johannesburg, South Africa: SABPP. 